\title{
12-Lipoxygenase Metabolites of Arachidonic Acid Mediate Metabotropic Glutamate Receptor-Dependent Long-Term Depression at Hippocampal CA3-CA1 Synapses
}

\author{
Steven J. Feinmark, ${ }^{1,2}$ Roxana Begum, ${ }^{1}$ Evgeny Tsvetkov, ${ }^{5}$ Ivan Goussakov, ${ }^{5}$ Colin D. Funk,${ }^{4}$ Steven A. Siegelbaum, ${ }^{1,3}$ \\ and Vadim Y. Bolshakov ${ }^{5}$ \\ ${ }^{1}$ Department of Pharmacology, ${ }^{2}$ Center for Molecular Therapeutics, and ${ }^{3}$ Howard Hughes Medical Institute, Center for Neurobiology and Behavior, \\ Columbia University, New York, New York 10032, ${ }^{4}$ Department of Pharmacology, Center for Experimental Therapeutics, University of Pennsylvania School \\ of Medicine, Philadelphia, Pennsylvania 19104, and 5Department of Psychiatry, McLean Hospital, Harvard Medical School, Belmont, Massachusetts 02478
}

Arachidonic acid metabolites have been proposed as signaling molecules in hippocampal long-term potentiation (LTP) and long-term depression (LTD) for $>15$ years. However, the functional role of these molecules remains controversial. Here we used a multidisciplinary biochemical, electrophysiological, and genetic approach to examine the function of the 12-lipoxygenase metabolites of arachidonic acid in long-term synaptic plasticity at CA3-CA1 synapses. We found that the 12-lipoxygenase pathway is required for the induction of metabotropic glutamate receptor-dependent LTD (mGluR-LTD), but is not required for LTP: (1) Hippocampal homogenates were capable of synthesizing the 12-lipoxygenase metabolite of arachidonic acid, 12(S)-hydroxyeicosa-5Z,8Z,10E,14Z-tetraenoic acid (HETE). (2) Stimulation protocols that induce mGluR-LTD lead to a release of 12-(S)-HETE from acute hippocampal slices. (3) A mouse in which the leukocyte-type 12-lipoxygenase (the neuronal isoform) was deleted through homologous recombination was deficient in mGluR-LTD, but showed normal LTP. (4) Pharmacological inhibition of 12-lipoxygenase also blocked induction of mGluR-LTD. (5) Finally, direct application of 12(S)-HPETE, but not 15(S)-HPETE, to hippocampal slices induced a long-term depression of synaptic transmission that mimicked and occluded mGluR-LTD induced by synaptic stimulation. Thus, 12(S)-hydroperoxyeicosa-5Z, 8Z, 10E, 14Z-tetraenoic acid (12(S)-HPETE), a 12-lipoxygenase metabolite of arachidonic acid, satisfies all of the criteria of a messenger molecule that is actively recruited for the induction of mGluR-LTD.

Key words: hippocampus; synaptic transmission; LTD; 12-lipoxygenase; retrograde messenger; metabotropic glutamate receptors; arachidonic acid

\section{Introduction}

A large number of signaling molecules have now been implicated in activity-dependent forms of long-term synaptic plasticity at hippocampal CA3-CA1 synapses. In fact, this complexity has led some to question the likelihood of our ever understanding the core signaling pathways involved in these processes (Sanes and Lichtman, 1999). One key problem in evaluating the role of a given signal transduction pathway is the difficulty in discriminating whether that pathway is actively recruited for the induction of synaptic plasticity or whether it serves a passive, permissive role necessary for the basal functioning of the plasticity machinery.

Before a biochemical cascade can be implicated as an active inductive signal for synaptic plasticity, several requirements must be met. First, at the biochemical level, the signaling cascade must

Received Aug. 4, 2003; revised 0ct. 21, 2003; accepted 0ct. 21, 2003.

This work was supported by the Whitehall Foundation (V.Y.B.), Esther A. and Joseph Klingenstein Fund (V.Y.B), and National Institutes of Health Grants NS44185 and NS45625 (V.Y.B.), HL53558 (C.D.F), and NS29832 (S.J.F.).We thank Dr. Robert R. Sciacca for statistical consultations, Yelena Gor for technical assistance with the GC/MS assay, and Iryna Voloshyna for maintaining the 12-L0 knock-out mouse colony.

Correspondence should be addressed to Dr. Steven J. Feinmark, Department of Pharmacology, Center for Molecular Therapeutics, Columbia University, 630 West 168th Street, New York, NY 10032. E-mail: sjf1@columbia.edu. Copyright $\odot 2003$ Society for Neuroscience $\quad 0270-6474 / 03 / 2311427-09 \$ 15.00 / 0$ be present in the neurons of interest and, importantly, must be activated during the induction of long-term plasticity. Second, inhibition of the cascade using highly selective drugs or genetic deletion must block the induction of plasticity. Third, exogenous application of the signaling molecule must induce plasticity independent of synaptic activity; moreover, this effect should occlude the subsequent induction of plasticity through synaptic activity. To date, only a handful of signaling cascades have passed these tests. Here we examine the role of 12(S)-hydroperoxyeicosa-5Z, 8Z, 10E, 14Z-tetraenoic acid [12(S)-HPETE], a 12-lipoxygenase (12-LO) metabolite of arachidonic acid (AA), in activity-dependent long-term synaptic plasticity at CA3-CA1 hippocampal synapses.

AA and its metabolites were first proposed as signaling molecules in hippocampal synaptic plasticity $>15$ years ago, based on initial studies in Aplysia that showed the importance of these molecules in short-term presynaptic inhibition (Piomelli et al., 1987a,b). Because AA and its metabolites are membranepermeant and can serve as both autocrine and paracrine messengers, they are particularly attractive as candidate retrograde messengers for forms of plasticity that are induced in the postsynaptic cell but expressed in the presynaptic cell. Subsequent studies have implicated these metabolites in long-term potentiation (LTP) 
(Williams et al., 1989) and long-term depression (LTD) (Drapeau et al., 1990; Bolshakov and Siegelbaum, 1995; Normandin et al., 1996). However, much of the evidence was based on the effects of high concentrations of relatively nonspecific blockers of the arachidonic acid cascade. Moreover, it has not been shown whether synaptic activity used to induce plasticity stimulates the production and release of AA metabolites. As a result, the status of these important signaling molecules in hippocampal plasticity remains highly questionable. Indeed, reports of a role of AA metabolites in induction of LTP (O'Dell et al., 1991) and LTD (Stanton, 1995) have been challenged.

Several lines of evidence led us to reinvestigate whether the AA pathway might be important for metabotropic glutamate receptor-dependent LTD (mGluR-LTD). Recently, mGluR-LTD was found to depend on the activation of p38 mitogen-activated protein kinase (p38 MAPK) (Bolshakov et al., 2000; Rush et al., 2002; Zhu et al., 2002), a kinase that can activate cytosolic phospholipase $\mathrm{A}_{2}\left(\mathrm{cPLA}_{2}\right)$ (Borsch-Haubold et al., 1997). This calcium-sensitive enzyme, which initiates the AA signaling cascade by liberating AA from membrane phospholipids, is highly expressed in hippocampal neurons (Kishimoto et al., 1999). Conversely, AA has been shown to stimulate p38 MAPK (Hii et al., 1998; Kalyankrishna and Malik, 2003), suggesting a positive feedback interaction between the two cascades that might contribute to the maintenance of long-term plasticity. Because mGluR-LTD is induced through a rise in $\mathrm{Ca}^{2+}$ in the postsynaptic CA1 neuron, but is expressed, at least partly, as a decrease in transmitter release from the presynaptic CA3 neuron, it has long been postulated that this form of plasticity requires a retrograde messenger (Bolshakov and Siegelbaum, 1994; Oliet et al., 1997). AA metabolites are one candidate for such a retrograde signal.

Here we show that the 12-lipoxygenase pathway of AA metabolism fulfills all of the criteria for an active inductive signal for mGluR-LTD at CA3-CA1 synapses. Using gas chromatographymass spectrometry, we detect the production and release of the 12-LO metabolite, 12-hydroxyeicosa-5Z,8Z,10E,14Z-tetraeonic acid (HETE), a stable product of 12-HPETE, from the hippocampus during LTD induction. Moreover, we find that mGluR-LTD is not induced in recombinant mice deficient in the "leukocytetype" 12-LO (the neuronal isoform; Watanabe et al., 1993; Sun and Funk, 1996), whereas LTP remains intact. Finally the AA metabolite 12(S)-HPETE mimics and occludes LTD induced by synaptic stimulation in wild-type mice. Combined with previous results showing that mGluR-LTD requires $\mathrm{PLA}_{2}$ activity (Bolshakov and Siegelbaum, 1995), our present findings provide strong evidence that the 12-LO cascade is critical for the induction of mGluR-LTD.

\section{Materials and Methods}

Electrophysiological recordings. Hippocampal slices (250-300 $\mu \mathrm{m})$ were prepared with a vibratome from 4- to 10-d-old (LTD experiments) or from 2-month-old (LTP experiments) C57BL/6J wild-type mice and 12-LO knock-out mice that had been backcrossed onto the C57BL/6 background (Sun and Funk, 1996). Slices were continuously superfused with a solution containing (in $\mathrm{mM}$ ): $119 \mathrm{NaCl}, 2.5 \mathrm{KCl}, 2.5 \mathrm{CaCl}_{2}, 1.0$ $\mathrm{MgSO}_{4}, 1.25 \mathrm{NaH}_{2} \mathrm{PO}_{4}, 26.0 \mathrm{NaHCO}_{3}, 10$ glucose, and 0.1 picrotoxin and equilibrated with $95 \% \mathrm{O}_{2}$ and $5 \% \mathrm{CO}_{2}, \mathrm{pH} 7.3-7.4$, at $20-23^{\circ} \mathrm{C}$. Whole-cell recordings of compound EPSCs were obtained from CA1 pyramidal cells with an EPC-9 amplifier and Pulse version 8.09 software (HEKA Elektronik, Lambrecht/Pfalz, Germany). Compound EPSCs were evoked by field stimulation of Schaffer collaterals by a bipolar electrode in stratum radiatum. The patch electrodes (3-6 $\mathrm{M} \Omega$ resistance) contained (in mM): $130 \mathrm{KCl}, 5 \mathrm{NaCl}, 1 \mathrm{MgCl}_{2}, 0.2$ EGTA, 10 HEPES, 2 MgATP, and 0.1 NaGTP (adjusted to pH 7.2 with $\mathrm{KOH}$ ). Series resis- tance was monitored throughout the experiments and ranged from $10-25 \mathrm{M} \Omega$. Currents were filtered at $1 \mathrm{kHz}$ and digitized at $5 \mathrm{kHz}$. The holding potential was $-70 \mathrm{mV}$.

The EPSC amplitude was measured as the difference between the mean current during a prestimulus baseline and the mean current over a $2 \mathrm{msec}$ window at the peak of the response. For LTD induction, the CA1 neuron was held under current-clamp conditions, and presynaptic inputs were stimulated for $3 \mathrm{~min}$ at $5 \mathrm{~Hz}$ frequency. Spontaneous mEPSCs were recorded in the presence of $1 \mu \mathrm{M}$ tetrodotoxin and analyzed with the MiniAnalysis Program version 5.4.1 (Synaptosoft Inc., Decatur, GA).

Field potentials from the CA1 stratum radiatum region were recorded with an extracellular recording electrode (4-6 M $\Omega$ ) filled with extracellular solution. To elicit field EPSPs, afferent fibers in the stratum radiatum were stimulated once every $10-30 \mathrm{sec}$ with bipolar tungsten electrodes. LTD was induced using either a $15 \mathrm{~min}$ period of $1 \mathrm{~Hz}$ stimulation or a $3 \mathrm{~min}$ period of $5 \mathrm{~Hz}$ stimulation.

Biochemistry. For homogenate experiments, hippocampi were dissected from adult mouse brains and homogenized in a Dounce glass tissue disrupter. The homogenate was subjected to a low-speed centrifugation $\left(2700 \times g, 5 \mathrm{~min}, 4^{\circ} \mathrm{C}\right)$ to remove debris and unbroken cells and then adjusted to $980 \mu \mathrm{g}$ of protein/ml of PBS. 12-LO activity was measured by transferring the homogenate to a tube that contained $\left[{ }^{3} \mathrm{H}_{8}\right] \mathrm{AA}$ (to a final concentration of $10 \mu \mathrm{M}$ and $2.5 \mu \mathrm{Ci} / \mathrm{nmol}$ ) for $10 \mathrm{~min}$ at $37^{\circ} \mathrm{C}$, stopped with two volumes of ice-cold acetone containing 12-HETE as an internal standard. Products were extracted and purified essentially as described (Steel et al., 1997) by sequential purification of 12-HETE by RP-HPLC followed by conversion of the product to its methyl ester and final purification on SP-HPLC. Products were quantified using a flowthrough radioactivity detector.

Production of 12-HETE by hippocampal slices in response to synaptic stimulation was measured by a stable isotope dilution gas chromatography-mass spectrometry (GC-MS) assay using tissue from animals that were 4- to 10-d-old. Superfusates from the tissue slices were collected every $5 \mathrm{~min}$, made up to $15 \%$ in ethanol, and stored at $-70^{\circ} \mathrm{C}$ until analyzed. Measured aliquots of the samples (typically 25\%) were spiked with $\left[{ }^{2} \mathrm{H}_{8}\right] 12(\mathrm{~S})$-HETE (5 ng) and acidified to $\mathrm{pH} 3$ with formic acid. The samples were applied to preconditioned $\mathrm{C}_{18}$ solid phase extraction columns (Varian Bond-Elut) and sequentially washed with water $(5 \mathrm{ml})$, $15 \%$ ethanol $(5 \mathrm{ml})$, and petroleum ether $(5 \mathrm{ml})$. The sample was then eluted with freshly redistilled ethyl acetate $(10 \mathrm{ml})$. 12-HETE was further purified from these lipid extracts by RP-HPLC as described above, and the 12-HETE fraction was collected. Purified 12-HETE was converted to its corresponding pentafluorobenzyl ester (PFB), trimethylsilyl ether (TMS), by mixing it with PFB bromide ( $5 \mu \mathrm{l})$ in acetonitrile $(50 \mu \mathrm{l})$ with $\mathrm{N}, \mathrm{N}$-di-isopropylethylamine $(10 \mu \mathrm{l})$ and allowing the reaction to continue at room temperature for $10 \mathrm{~min}$. After adding water to the reaction, the lipid esters were extracted into hexane. The hexane was removed under reduced pressure, and the resulting 12-HETE-PFB was mixed with $50 \mu \mathrm{l}$ of bis(trimethylsilyl)-trifluoroacetamide (BSTFA) in acetonitrile (1:1, vol:vol) and allowed to react at $65^{\circ} \mathrm{C}$ for $15 \mathrm{~min}$. Excess reactants were removed under reduced pressure, and the sample was dissolved in toluene for analysis on the GC-MS.

The HP5988 GC-MS was run in negative ion-chemical ionization mode with the ion source at $150^{\circ} \mathrm{C}$ and methane as the ionizing gas (at $\sim 1$ torr in the ion source). The GC injector was set to $240^{\circ} \mathrm{C}$ and the oven to $100^{\circ} \mathrm{C}$ and held for $1 \mathrm{~min}$ before ramping to $250^{\circ} \mathrm{C}$ at a rate of $20^{\circ} \mathrm{C} / \mathrm{min}$. The GC was fitted with a $15 \mathrm{~m}$ SP-2340 capillary column flowing with helium as a carrier gas at a constant head pressure of $52 \mathrm{kPa}$. The flow directly entered the ion source through a heated transfer line. The MS was set to monitor ions at $\mathrm{m} / \mathrm{z} 391$ which is the M-PFB ion for $\mathrm{d} 0-12$-HETE and $\mathrm{m} / \mathrm{z} 399$ which is the comparable ion for the internal standard $\mathrm{d} 8-$ 12-HETE. These ions account for nearly all of the ion current generated by a sample of 12-HETE under these conditions. The peak areas were determined, and the absolute amount of d0-HETE was calculated using a contemporaneous standard curve. These data were analyzed using a repeated measures ANOVA. Post hoc tests of differences from the baseline were done using a Bonferroni correction. 


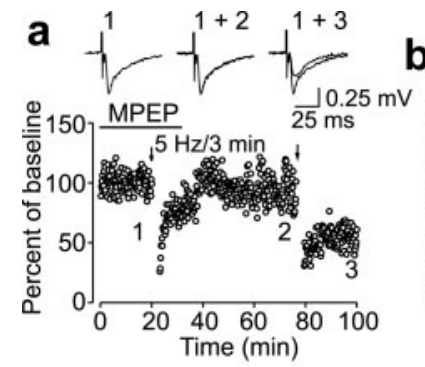

b
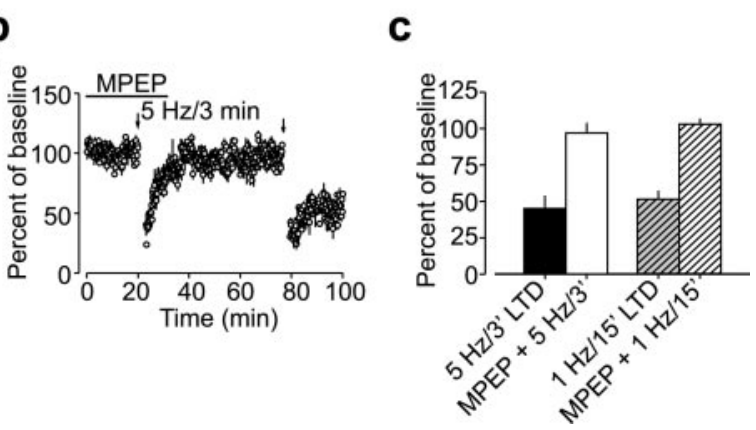

Figure 1. Activation of the $\mathrm{mGluR}_{5}$ receptor is required for the induction of mGluR-LTD. $a$, In a typical experiment, application of MPEP $(200 \mu \mathrm{M})$ during the LTD induction protocol (first arrow, $5 \mathrm{~Hz}$ stimulation of the Schaffer collateral pathway for $3 \mathrm{~min}$ ) blocked the induction of LTD. In the same slice, the $5 \mathrm{~Hz}$ stimulation protocol induced LTD after MPEP was washed out (second arrow). Horizontal bar indicates period of drug application. $b$, Average responses from all trials with MPEP $(200 \mu \mathrm{m} ; n=4)$ showing blockade of induction of LTD induced by presynaptic stimulation at $5 \mathrm{~Hz}$ frequency for 3 min (arrow). Horizontal bar indicates period of drug application. C, Summary of LTD experiments. LTD induced with a 3 min period of $5 \mathrm{~Hz}$ stimulation $(n=4)$ or LTD induced with a 15 min period of $1 \mathrm{~Hz}$ stimulation in normal solution $(n=9)$, or in the presence of MPEP $(n=6$; mean \pm SEM).

\section{Results}

mGluR-LTD at CA3-CA1 hippocampal synapses depends on $\mathrm{mGluR}_{5}$ receptor activation

Two forms of LTD have been characterized at hippocampal CA3CA1 synapses. Metabotropic glutamate receptor-dependent LTD predominates in neonatal rats and mice [ less than postnatal day 10 (P10)], whereas NMDA receptor-dependent LTD predominates in older animals ( $>$ P14). Here we focus on mGluR-LTD in neonatal mice, because this is the form of LTD that requires the p38 MAPK pathway (Bolshakov et al., 2000) and that has been linked to AA metabolism (Bolshakov and Siegelbaum, 1995).

In agreement with previous results, we found that prolonged low-frequency stimulation of the Schaffer collateral pathway (5 $\mathrm{Hz}$ for $3 \mathrm{~min}$ ) induced a prominent LTD at CA3-CA1 synapses in hippocampal slices from $\mathrm{P} 4-\mathrm{P} 10$ mice. This form of LTD was dependent on metabotropic glutamate receptors because it was blocked in the presence of the $\mathrm{mGluR}_{5}$ selective antagonist, 2-methyl-6-(phenylethynyl)-pyridine (MPEP) (200 $\mu \mathrm{M})$ (Fig. 1) (Gasparini et al., 1999; Fitzjohn et al., 1999). Thus, in the absence of MPEP, the LTD induction protocol reduced the average amplitude of the field EPSPs (fEPSPs) to $45 \pm 9 \%$ of its initial amplitude (measured $15 \mathrm{~min}$ after the $5 \mathrm{~Hz}$ stimulation). In the presence of MPEP, the fEPSP remained at $97 \pm 7 \%$ of its initial value after the delivery of the LTD induction protocol, significantly greater than the EPSP size during LTD induction in the absence of $\operatorname{MPEP}(n=4 ; t$ test; $t=4.66 ; p<0.01)$. We also found that mGluR-LTD was induced in these young mice using a stimulation paradigm consisting of a $15 \mathrm{~min}$ period of stimulation at $1 \mathrm{~Hz}$ (Fig. 1c), a protocol typically used to induce NMDARdependent LTD in slices from older animals (Dudek and Bear, 1992; Mulkey and Malenka, 1992). Similarly to LTD induced by the $5 \mathrm{~Hz}$ stimulation protocol, the LTD induced by $1 \mathrm{~Hz}$ stimulation was blocked when MPEP was applied during the induction protocol. The $1 \mathrm{~Hz}, 15 \mathrm{~min}$ LTD induction protocol was subsequently used for our biochemical measurements of arachidonic acid metabolites because it affords a longer time window for the collection of external perfusates during the stimulation period, compared to the $5 \mathrm{~Hz}, 3$ min protocol.

The effects of MPEP were readily reversible, because LTD could be induced in the same slice preparation after the antagonist was washed out (Fig. $1 a, b$, second arrow). Because the
$\mathrm{mGluR}_{5}$-type receptors are expressed in the postsynaptic CA1 neurons but not in the presynaptic CA3 neuron terminals (Pin and Duvoisin, 1995; Lujan et al., 1996), these results suggest the importance of postsynaptic receptor activation in mGluR-LTD.

To control for possible nonspecific effects of MPEP, we examined its action on NMDA receptor responses. NMDAR EPSCs were recorded using a whole-cell voltage clamp of CA1 neurons at a holding potential of $+30 \mathrm{mV}$ in the presence of CNQX. We found that application of 200 $\mu \mathrm{M}$ MPEP, the concentration used above to inhibit LTD, did not alter the amplitude of NMDAR currents. Thus, the NMDAR EPSC amplitude remained at $103.7 \pm 10 \%$ of its baseline value 15 min after application of MPEP ( $n=9$ cells; $t$ test, no significant difference, $t=0.8 ; p=0.43)$. The voltage dependence of the NMDAR currents was also unaffected by MPEP ( $n=5$, data not shown). Moreover, we found that application of $200 \mu \mathrm{M}$ MPEP had no effect on the size of LTP induced by $100 \mathrm{~Hz}$ tetanic stimulation (two trains of $100 \mathrm{~Hz}$ stimulation for $1 \mathrm{sec}$, applied $20 \mathrm{sec}$ apart). Thirty minutes after induction of LTP in the absence of MPEP, the fEPSPs were enhanced to $174.5 \pm 10 \%$ of their initial value $(n=6)$. We observed a similar enhancement of the fEPSPs, to $177 \pm 9 \%$ of their initial value, when the LTP was induced in the presence of $200 \mu \mathrm{M}$ MPEP $(n=5)$, which was not significantly different from LTP under control conditions ( $p=0.87$; $t$ test).

Finally, we found that MPEP was also effective in inhibiting LTD when applied at a concentration of $5 \mu \mathrm{M}$, which was previously shown to be specific for the $\mathrm{mGluR}_{5}$ type receptor (Gasparini et al., 1999). Thus, when the $15 \mathrm{~min}$ period of $1 \mathrm{~Hz}$ synaptic stimulation was applied in the presence of $5 \mu \mathrm{M}$ MPEP, the field EPSP remained at $96.9 \pm 7.1 \%$ of its initial value, $25 \mathrm{~min}$ after the delivery of the LTD induction protocol. This effect of MPEP was also reversible, because LTD could be induced in the same slice preparation after the antagonist was washed out. In the absence of MPEP, the LTD induction protocol reduced the average amplitude of the field EPSPs to $54.6 \pm 3 \%$ of its initial amplitude ( 25 min after the $1 \mathrm{~Hz}$ stimulation), significantly different from the EPSP size after the LTD-inducing stimulation in the presence of $\operatorname{MPEP}(n=4 ; t$ test; $t=5.83 ; p<0.01)$. These data indicate that the induction of mGluR-LTD specifically depends on the activation of $\mathrm{mGluR}_{5}$.

\section{The 12-lipoxygenase metabolite 12-HETE is released during induction of mGluR-LTD}

Because 12(S)-HPETE has been implicated in synaptic inhibition in Aplysia (Piomelli et al., 1987a,b), we asked whether this metabolite could be a signaling molecule for mGluR-LTD. We first confirmed the presence of 12-LO enzyme activity in tissue homogenates of the murine hippocampus using a well established HPLC biochemical assay (Piomelli et al., 1987a; Steel et al., 1997). Because two isoforms of the enzyme exist, we also compared the enzyme activity in hippocampal homogenates from wild-type mice (Fig. 2, solid line) to the activity in homogenates from mice in which the "leukocyte-type" 12-LO (the neuronal isoform) had been genetically deleted (Watanabe et al., 1993; Sun and Funk, 1996). 12-LO activity was decreased by nearly two-thirds in ho- 


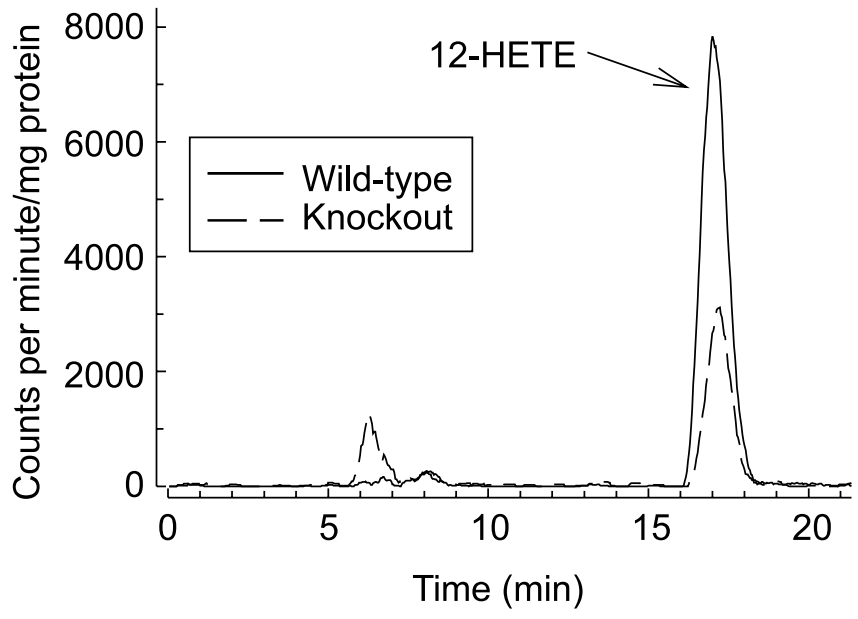

Figure 2. "Leukocyte-type" 12-L0 enzyme activity is present in wild-type murine hippocampus. When hippocampal homogenates from wild-type (solid line) or 12-L0 K0 mice (broken line) were incubated with [ $\left.{ }^{3} \mathrm{H}\right] \mathrm{AA}(25 \mu \mathrm{Ci} ; 2.5 \mu \mathrm{Ci} / \mathrm{nmol})$, a single peak of radiolabeled material corresponding to 12-HETE was generated. The bulk of the enzyme activity in the homogenate is attributable to the leukocyte-type enzyme with the remainder arising from contamination of the preparation with platelets which express a unique 12-L0 isoform. In this trial, typical of four, $7890 \mathrm{cpm}$ of 12 -HETE were generated per milligram of protein. The radioactivity eluting at the solvent front ( $\sim 6 \mathrm{~min}$ ) is a mixture of polar lipids unrelated to $L O$ metabolism.

mogenates from the knock-out animals (Fig. 2, broken line), a change that was statistically significant when compared with wild-type mice ( $p<0.05 ; n=4)$. The residual 12 -LO activity likely reflects the presence of some contamination of the homog- enate by platelets, which express a distinct 12-LO isoform (Chen et al., 1994).

Next, we turned to studies of intact hippocampal slices from mice at the developmental stage at which mGluR-LTD is prominent (P4-P10). Using a sensitive and specific stable isotope dilution GC-MS assay for 12-HETE, the stable breakdown product of 12-HPETE, we confirmed the presence of 12-LO in neonatal hippocampus (data not shown), supporting the hypothesis that lipoxygenase activity may underlie regulation of synaptic function. But, are 12-LO metabolites of AA released during induction of LTD using low-frequency presynaptic stimulation? To explore this question, we performed parallel electrophysiological and biochemical studies during LTD induction in hippocampal slices.

12-HETE was quantified in samples of the external perfusion solution that were taken every 5 min before, during, and after the induction of mGluR-LTD. 12-HETE levels in the perfusate increased significantly during the induction of LTD, using a $15 \mathrm{~min}$ period of $1 \mathrm{~Hz}$ synaptic stimulation, and remained elevated for 15 min after the end of the induction protocol, during the initial stages of LTD (Fig. 3a). Maximal 12-HETE levels were significantly increased to $198 \pm 59 \%$ of their baseline value of 250 pg/slice per minute ( $n=9 ; p<0.05$ when compared to baseline). In these same experiments, the amplitude of the fEPSP recorded 40 min after LTD induction was decreased to $51.1 \pm 6 \%(n=9)$ of its initial value (Fig. $3 b$ ). An increase in 12-HETE production was specifically linked to mGluR activation, because MPEP (200 $\mu \mathrm{M}$ ) blocked both the increase in 12-HETE production (Fig. 3c) and the induction of LTD (Fig. $3 d$ ). Thus, 40 min after the LTD induction protocol was delivered in the presence of MPEP, the fEPSP amplitude remained at $102.7 \pm 4 \%$ of its initial value $(n=$ 6 ; statistically different from the magnitude of LTD observed without MPEP; $t=7.04 ; p<0.0001)$. a

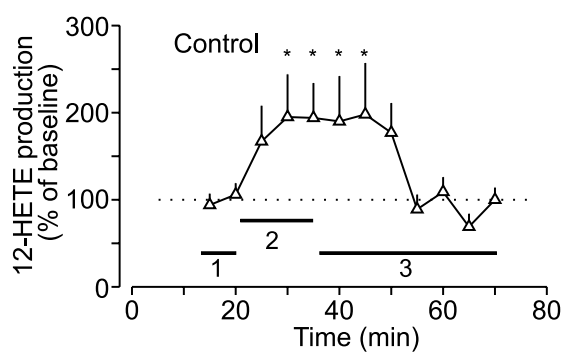

\section{C}

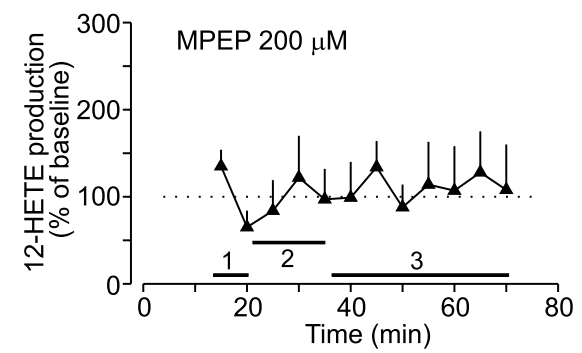

b

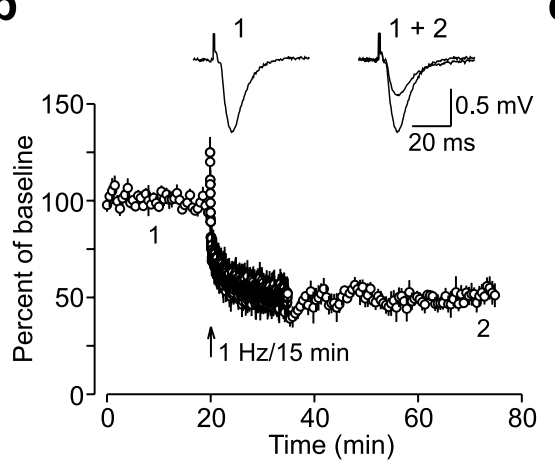

d

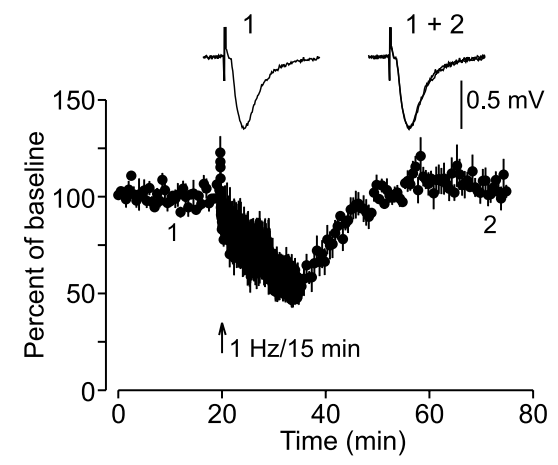

Figure 3. 12-HETE production was enhanced during induction of mGluR-LTD. a, Normalized values of 12-HETE production are plotted as a function of time in 5 min bins during baseline conditions (1), during $1 \mathrm{~Hz}$ stimulation (2), and after LTD induction (3). LTD-inducing stimulation ( $1 \mathrm{~Hz} / 15 \mathrm{~min}$ ) significantly enhanced the amount of 12 -HETE released from the stimulated slice into the bath solution ( $p<0.05$ versus baseline; $n=9$ ). $b$, LTD of fEPSP recorded from the same slices that were used for the biochemical experiments shown in $a(n=9)$. c, mGluR ${ }_{5}$ antagonist MPEP $(200 \mu \mathrm{M})$ blocked the increase in 12-HETE production during induction of mGluR-LTD $(n=6)$. $d$, LTD offEPSP in the same experiments as in c was blocked in the presence of MPEP $(n=6)$. Error bars indicate SEM.

\section{LTD is blocked in neonatal 12-LO knock-out mice}

To further explore the role of $12-\mathrm{LO}$ in synaptic plasticity, we analyzed 12-LO knock-out mice deficient in the neuronal lipoxygenase isoform (Watanabe et al., 1993; Sun and Funk, 1996). Basal synaptic transmission in the 12-LO-deficient mice appeared normal. Thus, EPSCs obtained in whole-cell recordings from CA1 neurons in response to stimulation of the Schaffer collateral inputs in hippocampal slices from wild-type and 12-LO knockout mice (P4-P10) were similar in size and time course (Fig. 4a). Paired-pulse facilitation (PPF) of the EPSC, an index of presynaptic function, was also similar in wildtype and 12-LO knock-out mice. Thus, $\mathrm{PPF}$, measured at a $50 \mathrm{msec}$ interstimulus interval, was equal to $1.7 \pm 0.08$ in wildtype mice ( $n=10$ slices, 4 mice) compared with $1.6 \pm 0.098$ in 12 -LO knock-out mice ( $n=8$ slices, 4 mice; no significant difference; $t$ test; $t=0.25 ; p=0.8$ ).

In contrast to the normal basal synaptic transmission, mGluR-LTD was absent in the 12-LO knock-out mice when assessed by two different protocols. We first measured the extent of mGluR-LTD in wholecell recordings of the EPSC from individ- 

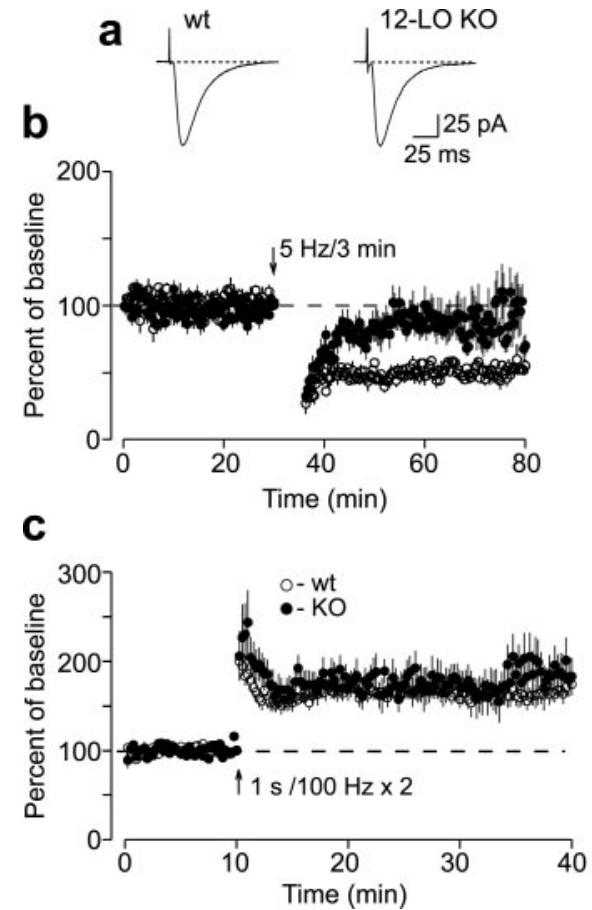

\section{e}
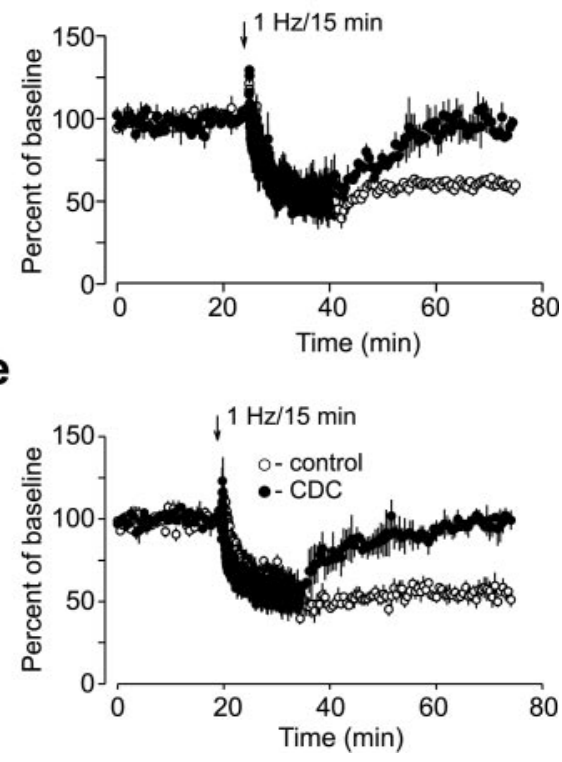

Figure 4. LTD and LTP in wild-type versus 12 -L0 knock-out mice. $a$, Examples of EPSCs recorded in slices from wild-type mice (left) and mutant mice (right). b, LTD of EPSCs from whole-cell recordings in CA1 neurons after $5 \mathrm{~Hz}$ stimulation for 3 min. LTD was absent in slices from 4- to 10-d-old 12-L0 knock-out mice (filled symbols; $n=12$ cells, 5 mice). The same stimulation protocol induced robust LTD in slices from wild-type mice of the same age (open symbols; $n=6$ cells, 4 mice). c, LTP summary graphs for wild-type ( $n=10$ slices, 4 mice) and 12-L0 knock-out adult mice ( $n=13$ slices, 4 mice). LTP of field EPSPs was induced by two trains of $100 \mathrm{~Hz}$ tetanic stimulation, each lasting $1 \mathrm{sec}$, spaced 20 sec apart. $d$, Low-frequency stimulation (1 Hz for $15 \mathrm{~min}$ ) induced LTD of the field EPSPs in slices from wild-type mice ( $n=9$ slices, 6 mice), but not in slices from 12 -L 0 knock-out mice ( $n=4$ slices, 4 mice).e, Low-frequency stimulation (1 Hz for $15 \mathrm{~min}$ ) induced LTD of the field EPSPs in slices from wild-type mice under control conditions ( $n=5$ slices, open symbols), but not in the presence of the 12-L0 inhibitor $\operatorname{CDC}(10 \mu \mathrm{M})(n=5$ slices, filled symbols). Error bars indicate SEM.

ual CA1 neurons after a 3 min period of $5 \mathrm{~Hz}$ stimulation of the Schaffer collateral pathway. In wild-type mice, this induction protocol depressed the EPSC to $49.9 \pm 4 \%$ of its initial value $(n=$ 6 cells $/ 4$ mice) (Fig. $4 b$ ). In contrast, in the 12-LO knock-out mice, this stimulation protocol induced only a transient decrease in the EPSC, with little or no long-term depression. Thus, 15 min after delivery of the $5 \mathrm{~Hz}$ period of synaptic stimulation, the EPSC in the mutant mice had recovered to $93.7 \pm 10 \%$ of its initial value (Fig. $4 b$, filled circles) ( $n=12$ cells $/ 5$ mice), significantly different from the extent of LTD in wild-type mice $(t=3.37$; $p<$ 0.005)

A defect in mGluR-LTD after deletion of 12-LO was also observed in recordings of the extracellular field EPSP using a $15 \mathrm{~min}$ period of $1 \mathrm{~Hz}$ synaptic stimulation. This induction protocol reduced the fEPSP to $60 \pm 2.7 \%$ ( $n=9$ slices, 6 mice) of its original amplitude in slices from wild-type mice (Fig. $4 d$ ) but again caused only a transient suppression in the 12-LO knockout mice. Thus, $30 \mathrm{~min}$ after the LTD induction protocol, the fEPSP had returned to $101.2 \pm 9.7 \%$ of its initial value (Fig. $4 d$ ) ( $n=4$ slices, 4 mice). Hence, the extent of LTD was significantly less in the $\mathrm{KO}$ mice than that observed in wild-type mice $(t=$ 5.54; $p<0.0002)$.

The above results demonstrate that mice deficient in 12-LO show a clear deficit in mGluR-LTD that is pronounced and independent of the specific stimulation protocol used to induce plasticity. Moreover, this deficit is specific to synaptic depression, because we find that long-term potentiation, a form of synaptic regulation that opposes LTD, is not altered in the 12-LO knock- out animals. We examined LTP at CA3CA1 synapses in slices from adult mice (2months-old), where the magnitude of LTP is much larger than it is in neonatal animals. Induction of LTP using $100 \mathrm{~Hz}$ tetanic stimulation of the Schaffer collateral pathway (two trains lasting $1 \mathrm{sec}$ each spaced $20 \mathrm{sec}$ apart) caused an increase in the fEPSP to $162.7 \pm 9.8 \%$ of its baseline value in wild-type mice ( $n=10$ slices, 4 mice) (Fig. $4 c$ ) and to $171.6 \pm 12 \%$ of its initial value in the 12 -LO knock-out mice ( $n=13$ slices, 4 mice) (Fig. $4 c$ ) (no significant difference from wild-type mice; $t=$ $0.61 ; p=0.55)$. Thus, the $12-\mathrm{LO}$ pathway is necessary for the induction of mGluRLTD, but not for $100 \mathrm{~Hz}$ LTP at CA3-CA1 synapses.

To obtain independent support for the conclusion that $12-\mathrm{LO}$ is required for mGluR-LTD, we tested the ability of the 12-LO inhibitor, cinnamyl-3,4dihydroxy- $\alpha$-cyanocinnamate (CDC) (10 $\mu \mathrm{M})$ to block induction of LTD in wildtype mice (Cho et al., 1991). We found that LTD was completely blocked when the induction protocol was delivered in the presence of the 12-LO inhibitor (Fig. 4e). Thus, 30 min after the delivery of the LTD induction protocol in the absence of the inhibitor, the EPSP was reduced to $52.9 \pm 3 \%$ ( $n=5$ slices) of its initial value. In contrast, the EPSP remained at $95.4 \pm 2 \%$ ( $n=5$ slices) of its baseline value when the induction protocol was delivered in the presence of CDC, indicating a significant block of LTD ( $t$ test, $t=$ 8.04; $p<0.001)$. This finding is fully consistent with the results obtained in 12-LO KO mice.

\section{2(S)-HPETE mimics and occludes LTD}

If the 12-LO pathway is actively recruited to induce mGluR-LTD, direct application of 12(S)-HPETE to hippocampal slices should both mimic and occlude the synaptic depression seen during long-term synaptic plasticity. Indeed, addition of 12(S)-HPETE $(100 \mathrm{nM})$ to the external artificial CSF produced a progressive decrease in the amplitude of the EPSC in wild-type mice (Fig. $5 a$ ). The magnitude of the EPSC was reduced to $51.9 \pm 12 \%$ of its baseline value $(n=6) 30 \mathrm{~min}$ after the start of application of 12( $S$ )-HPETE. This degree of inhibition is similar to the decrease in the EPSC in wild-type mice during mGluR-LTD (Fig. $4 a)(t=$ $0.14 ; p=0.89)$, suggesting that the action of $12(S)$-HPETE and LTD are related (see also below). Furthermore, the effect of 12(S)-HPETE on the EPSC was specific, because a closely related product of 15-lipoxygenase, 15( S)-HPETE (100 nM), had no effect on the size of the EPSC (Fig. $5 c$ ). Thus, the EPSC amplitude 15 min after application of 15(S)-HPETE was $98.9 \pm 5 \%$ of its initial value $(n=6 ; t=0.44 ; p=0.66)$.

Finally, we found that $12(S)$-HPETE must act downstream of 12-LO because this metabolite produced a similar sized depression of the EPSC in slices from the 12-LO knock-out mice as it did in wild-type mice (Fig. 5b). Thus, the EPSC was depressed to $52.7 \pm 7 \%$ of its initial value in the mutant mice $(n=6)$, a value that does not differ significantly from similar trials in slices from 
wild-type mice $(p=0.9)$. Furthermore, the finding that acute application of 12( $S$ )-HPETE caused a normal sized synaptic depression demonstrates that the lack of LTD in the 12-LO knock-out mice was not a result of a developmental defect.

Strong support for the view that the synaptic depression produced by $12(S)$ HPETE is causally related to LTD comes from our finding that the two forms of synaptic depression occluded each other. Thus, when 12(S)-HPETE was applied to hippocampal slices after the induction of LTD using $5 \mathrm{~Hz}$ synaptic stimulation, the normal depressant effect of this metabolite on synaptic transmission was blocked (Fig. $5 d)$. The EPSC amplitude was reduced to $52.9 \pm 1.8 \%$ of its initial value when measured $30 \mathrm{~min}$ after the induction of LTD. However, application of 12(S)-HPETE after the induction of LTD caused no further decrease in synaptic transmission. Fifteen minutes after 12(S)-HPETE, the EPSC amplitude remained equal to $54.2 \pm 0.9 \%$ of its initial baseline value before induction of LTD $(n=2)$. Conversely, an initial application of $12(S)$-HPETE produced a depression of synaptic transmission that occluded further depression of the EPSC after subsequent delivery of the $5 \mathrm{~Hz}$ LTD induction protocol (Fig. 5e). Twenty minutes after the beginning of 12(S)-HPETE application, the EPSC amplitude was reduced to $55 \pm 3 \%$ of its initial value. Subsequent initiation of the LTD induction protocol caused no significant effect, with EPSC amplitude equal to $52.3 \pm 4 \%$ of its initial baseline value $(n=4$; no significant difference; $t$ test; $t=0.59 ; p=0.58$ ). To determine whether the occlusion of LTD by $12(S)$-HPETE was specific, we tested whether 12(S)-HPETE would interfere with short-term synaptic depression induced by another neuromodulatory agonist, adenosine (Fig. $5 g$ ). In the presence of 12(S)-HPETE, which reduced the amplitude of the EPSC to $49.7 \pm 6 \%$ of its baseline value, addition of adenosine $(50 \mu \mathrm{M})$ induced a further depression of the EPSC amplitude, decreasing the EPSC to $31.7 \pm$ $8 \%$ of its initial baseline value before $12(S)$-HPETE $(n=4)$. These results provide a strong argument that $12(S)$-HPETE plays a causal and specific role in the induction of LTD.

\section{2(S)-HPETE shares a similar locus of synaptic action} as mGluR-LTD

If the depression induced by $12(S)$-HPETE is causally related to mGluR-LTD, the lipoxygenase metabolite should share a similar locus of synaptic action as mGluR-LTD. Previous studies showed that induction of mGluR-LTD had no effect on the spontaneous mEPSC amplitude but caused a marked change in the coefficient d

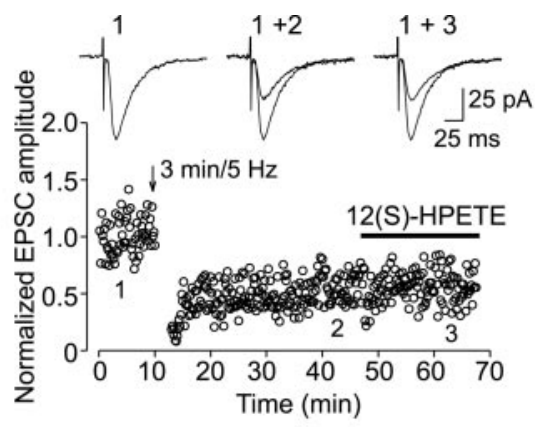

e
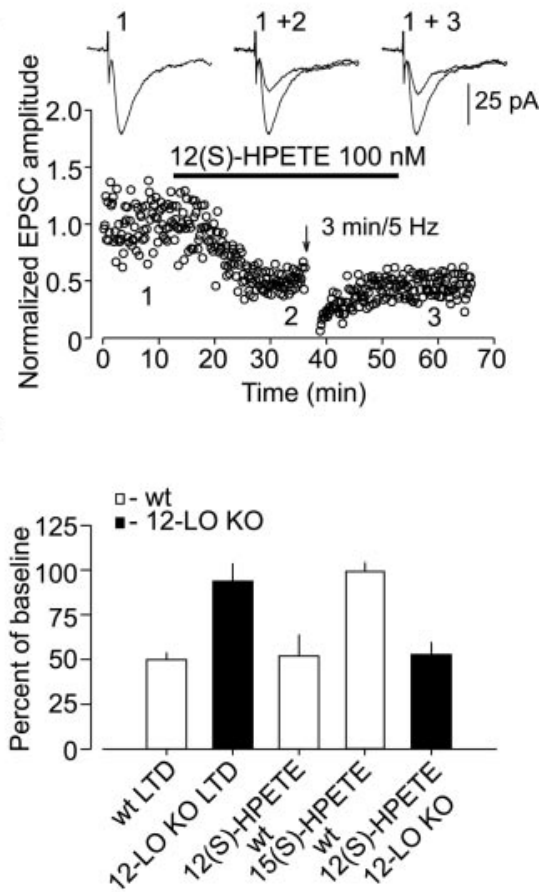

g

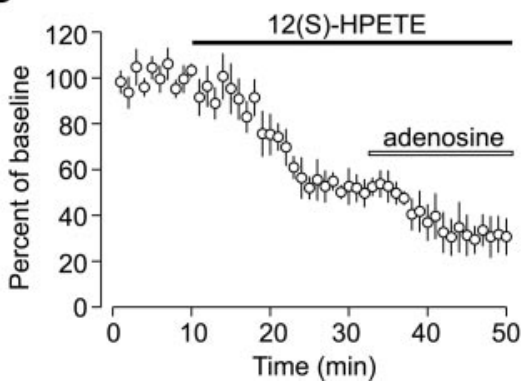

Figure 5. 12(S)-HPETE mimicked and occluded LTD. $a$, Effect of 12(S)-HPETE on EPSC in slices from wild-type mice $(n=6) \cdot b$, 12(S)-HPETE-induced depression of EPSC in slices from 12-L0 knock-out mice $(n=6)$. c, Application of 15( S)-HPETE did not affect the EPSC amplitude in slices from wild-type mice $(n=6)$ ). $d$, Induction of LTD with $5 \mathrm{~Hz}$ stimulation (arrow) occluded the subsequent effect of 12(S)-HPETE (100 nm) on the EPSC amplitude. Representative experiment showing EPSC traces during baseline recording (1), during LTD (2), and during 12(S)-HPETE application (3). e, 12(S)-HPETE (100 nM) application occluded electrically induced LTD (arrow). f, Summary of LTD data and effects of 12(S)-HPETE in wild-type and 12-L0 knock-out mice. $g$, 12(S)-HPETE does not block adenosine-induced synaptic depression. After LTD was induced by application of 12( S)-HPETE (100 $\mathrm{nm})$, subsequent addition of adenosine (50 $\mu \mathrm{m})$ induced an additional depression $(n=4)$. of variation (CV) of the evoked EPSC (SD divided by mean EPSC response), two hallmarks of a presynaptic effect (Bolshakov and Siegelbaum, 1994). We found that application of 12(S)-HPETE had a similar action on these characteristic parameters. Thus, the action of $12(S)$-HPETE on the EPSC was accompanied by marked changes in the $\mathrm{CV}$, consistent with a presynaptic effect (Fig. 6). Furthermore, 12(S)-HPETE (100 nM) application had no effect on the size of spontaneous mEPSCs (Fig. 7), although it 

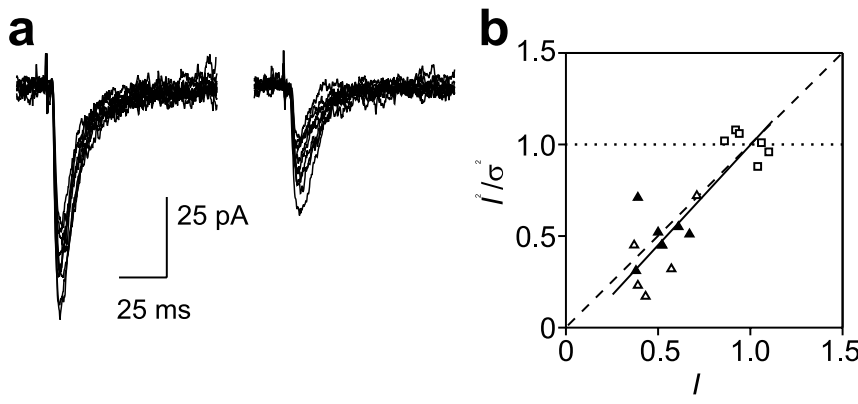

Figure 6. 12(S)-HPETE-induced synaptic depression produces a significant change in coefficient of variation, consistent with a presynaptic effect. $a$, Superimposed EPSCs were recorded under baseline conditions (left) and after application of 12(S)-HPETE (100 nM) (right). b, Scatterplot showing effects of lipoxygenase metabolite application on values of $1 / \mathrm{CV}^{2}\left(I^{2} / \sigma^{2}\right.$, where $/$ is mean EPSC and $\sigma^{2}$ is EPSC variance) versus effects on I. Data shown for 12(S)-HPETE application in slices from wild-type mice (open triangles; $n=6$ ) or 12-L0 knock-out mice (filled triangles; $n=6$ ), and 15(S)-HPETE application in slices from wild-type mice (open squares; $n=6)$. Each symbol is a measurement from a separate slice. All values were normalized by their baseline values before lipid application. There was a significant correlation between changes in $I$ and $I^{2} / \sigma^{2}$ (solid line; correlation coefficient; $r=0.86$ ), consistent with presynaptic changes. Horizontal dotted line demonstrates the predicted relation between changes in $/$ and $I^{2} / \sigma^{2}$ if the effect of the metabolite was purely postsynaptic.

did depress the amplitude of the evoked EPSCs (Fig. 5). Thus, mean mEPSC amplitudes in the absence and presence of $12(S)$ HPETE were $7.79 \pm 1.1 \mathrm{pA}(n=6)$ and $7.83 \pm 1.2 \mathrm{pA}(n=6)$, respectively (paired $t$ test; $t=0.1 ; p=0.9)$. 12( $S$ )-HPETE application also did not alter the CV of the mEPSC amplitude ( $p=$ 0.46 ) (Fig. $7 d$ ), but had a significant effect on mEPSC frequency. Thus, the mEPSC frequency was significantly changed from $0.66 \pm 0.2 \mathrm{~Hz}$ under baseline conditions to $0.45 \pm 0.2 \mathrm{~Hz}$ after application of $12(S)$-HPETE $(n=6 ; p<0.05)$. This is consistent
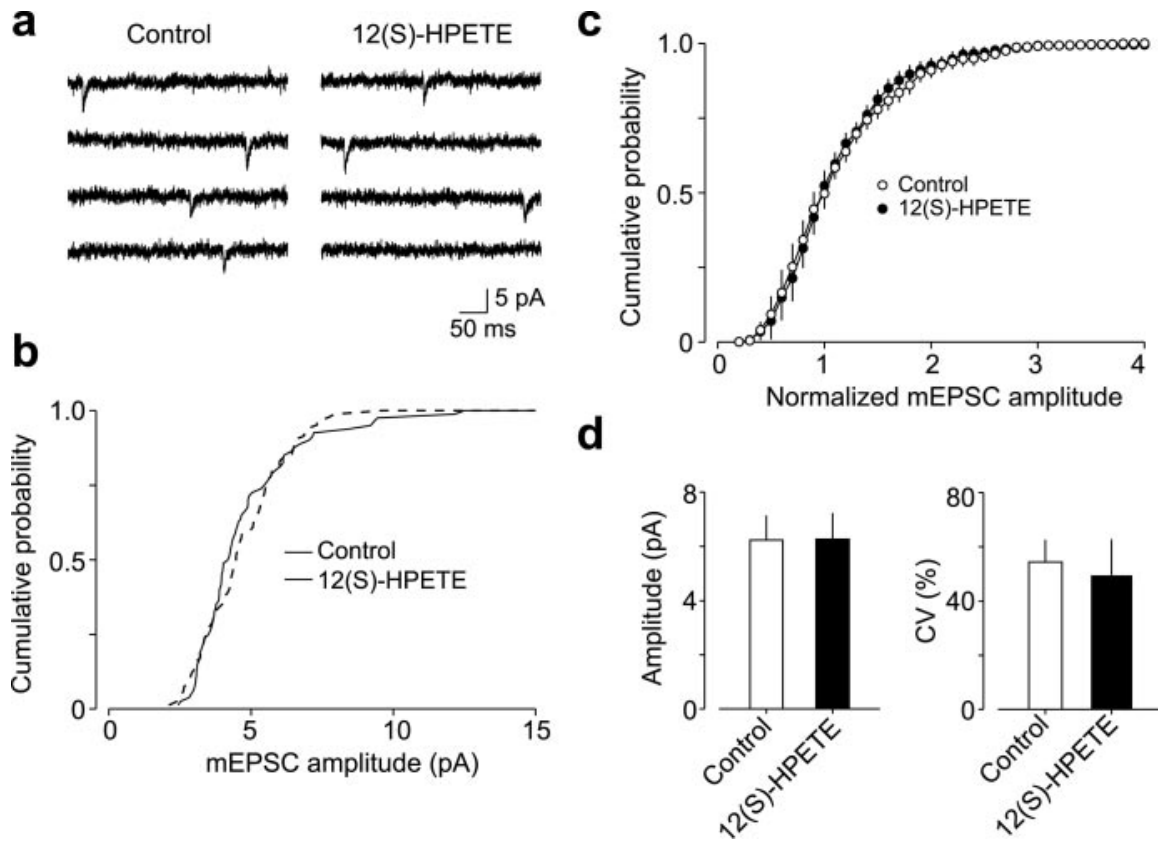

Figure 7. 12(S)-HPETE had no effect on the mEPSC amplitude. $a$, Representative mEPSCs recorded from a CA1 cell at a holding potential of $-70 \mathrm{mV}$ under baseline conditions (left) and after 12 (S)-HPETE (100 nM) was added (right). $b$, Cumulative amplitude histograms of $m E P S C$ s recorded from the same cell as in a under baseline conditions (solid line) and after 12(S)-HPETE was applied (dashed line). c, Averaged amplitude histograms of mEPSCs recorded before (open symbols) and after (filled symbols) 12(S)HPETE application ( $n=6$ cells). For the cumulative graphs, responses were normalized by the median amplitude of the mEPSCS, collected under baseline conditions, in each individual experiment. $d$, Summary plot of mEPSC data. Averaged values of mEPSC parameters, mean peak amplitude (left), and CV (right). Error bars indicate SEM.

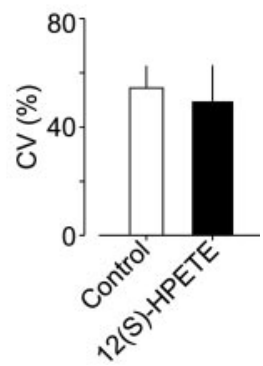

with the notion that $12(S)$-HPETE acts presynaptically to decrease transmitter release. Even though the interpretation of results using $\mathrm{CV}$ are open to some question, the correlation between the action of $12(S)$-HPETE and mGluR-LTD provides strong support for the view that the lipoxygenase cascade mediates this form of synaptic plasticity.

\section{Discussion}

Using a combined biochemical, genetic, and electrophysiological approach, we demonstrated that the 12-lipoxygenase pathway of AA metabolism plays an essential role in the induction of $\mathrm{mGluR}$ LTD at hippocampal CA3-CA1 synapses. Thus, the 12-LO metabolite of AA, 12( $S$ )-HPETE (or a downstream product of its metabolism), satisfies all the criteria of a signaling molecule that is actively recruited by synaptic activity for the induction of longterm synaptic plasticity: (1) 12-LO is expressed in the hippocampus at a developmental stage when mGluR-LTD is robust ( $\mathrm{P} 4-$ P10), (2) 12-LO metabolites are released from hippocampal slices, and production of 12-HETE is significantly enhanced during the induction of mGluR-LTD. Both LTD and 12-HETE release are mediated by activation of $\mathrm{mGluR}_{5}$. (3) Furthermore, release of 12-LO metabolites is necessary for the induction of mGluR-LTD because this form of synaptic plasticity is blocked in 12-LO knock-out mice and by application of a 12-LO inhibitor in wild-type mice. (4) Direct application of 12(S)-HPETE to hippocampal slices produces synaptic depression that mimics and occludes mGluR-LTD; moreover induction of LTD occludes synaptic depression produced by $12(S)$-HPETE, indicating that both processes share a common mechanism. Additionally, we have previously shown that pharmacological inhibition of phospholipase $\mathrm{A}_{2}$ activity, an enzyme upstream of 12 - $\mathrm{LO}$ that liberates arachidonic acid from membrane phospholipids, blocks the induction of mGluR-LTD (Bolshakov and Siegelbaum, 1995).

What are the upstream factors that stimulate AA release and 12(S)-HPETE production during the induction of LTD? What are the downstream targets of AA and its 12-LO metabolites? Although definitive answers to such questions are lacking, we have already suggested that the p38 MAPK cascade likely serves as a signaling partner with the AA cascade during the induction of LTD (Bolshakov et al., 2000). Because AA and its metabolites stimulate p38 MAPK and p38 MAPK activates PLA (Hii et al., 1998; Kalyankrishna and Malik, 2003), the two signaling pathways may function in a positive feedback loop to maintain their state of activation during and after the induction of LTD.

Is the $12-\mathrm{LO}$ activity that is required during the induction of LTD localized in the presynaptic CA3 neuron or postsynaptic CA1 neuron? The induction of mGluRLTD has a clear postsynaptic component: (1) $\mathrm{mGluR}_{5}$ is localized to the CA1 neuron, (2) induction of mGluR-LTD requires a rise in intracellular $\mathrm{Ca}^{2+}$ in the postsynaptic CA1 neuron (Bolshakov and Siegelbaum, 1994), and (3) the p38 MAPK required for $\mathrm{mGluR-LTD}$ has also been localized to the CA1 neuron (Bolshakov et 
al., 2000). These postsynaptic signaling events suggest that a $\mathrm{Ca}^{2+}$-sensitive CPLA $_{2}$ (Yoshinara and Watanabe, 1990) and 12-LO may also be localized to the postsynaptic CA1 neuron.

In contrast to its postsynaptic site of induction, mGluR-LTD has a prominent presynaptic component of expression. Electrophysiological studies, based on quantal analysis (Bolshakov and Siegelbaum, 1994) or measurements of changes in paired pulse facilitation (Oliet et al., 1997; Watanabe et al., 2002), suggest that mGluR-LTD is associated with a decrease in transmitter release from the presynaptic terminals. An alteration in transmitter release during mGluR-LTD has been recently confirmed using twophoton imaging of the rate of release from presynaptic terminals of FM 1-43, a fluorescent marker of synaptic vesicle cycling ( $\mathrm{Za}$ kharenko et al., 2002).

The finding that LTD is induced postsynaptically but expressed presynaptically has led to the hypothesis that a retrograde messenger must be released from the postsynaptic CA1 neuron to alter transmitter release from the presynaptic CA3 neuron. Because of their membrane permeability, 12-LO metabolites such as $12(S)$-HPETE are attractive candidates for such retrograde messengers, although our present data do not rule out a postsynaptic locus of their action. A related group of lipids, the endocannabinoids, have also been implicated in synaptic plasticity and have been shown to be released in response to mGluR activation. Recent work has shown that although these lipids do cause a short-term depression, they do not account for mGluR-LTD in the CA1 region of the hippocampus (Rouach and Nicoll, 2003).

What are the presynaptic targets of a putative retrograde signal that downregulates glutamate release at CA3-CA1 synapses during mGluR-LTD? Presynaptic voltage-gated ion channels represent one potential target of 12-LO metabolites of AA (Fitzsimonds and Poo, 1998; Manzoni and Williams, 1999). Consistent with this notion, presynaptic inhibition of synaptic transmission in Aplysia sensory neurons induced by the neuroactive peptide FMRFamide is mediated by 12 -LO metabolites of AA, specifically 12-HPETE (Piomelli et al., 1987b). 12-HPETE induces membrane hyperpolarization by activating the S-type $\mathrm{K}^{+}$channel, which can contribute to a decrease in action potential duration, leading to a decrease in $\mathrm{Ca}^{2+}$ influx that inhibits neurotransmitter release. The TREK family of two pore-domain $\mathrm{K}^{+}$channels is likely to represent the mammalian ortholog of the Aplysia S-K ${ }^{+}$ channel (Patel et al., 2001). Some TREK channels are also activated by $\mathrm{AA}$, and these channels are expressed in hippocampal neurons (Hervieu et al., 2001; Medhurst et al., 2001; Talley et al., 2001). Furthermore, 12-LO products have been found to attenuate both the depolarization-induced release of glutamate and the depolarization-induced increase in $\mathrm{Ca}^{2+}$ influx in hippocampal mossy fiber synaptosomes (Freeman et al., 1991). Finally, 12 -HETE potently activates large-conductance $\mathrm{Ca}^{2+}$-activated $\mathrm{K}^{+}$currents, and thus might be implicated in modulation of presynaptic excitability (Zink et al., 2001).

In addition to ion channels, a retrograde signal might directly target the presynaptic release machinery, such as synaptic vesicle proteins and docking proteins (Cowan et al., 2001). The finding that mGluR-LTD can cause a switch in the mode of vesicular exocytosis from full fusion to the transient opening of a fusion pore (Zakharenko et al., 2002) is consistent with a direct regulation of the release process. Such hypotheses can be tested in the future, using a combination of electrophysiological and imaging techniques on hippocampal slices from mutant mice lacking specific proteins implicated in release and its modulation. Regardless of the precise molecular mechanisms involved in the long-term depression of glutamate release during mGluR-LTD, ours is the first study in mammals that links release of the identified diffusible factor, 12(S)-HPETE, with a specific mechanism of longterm synaptic plasticity. The fact that the same biochemical pathway is implicated in the inhibitory regulation of synaptic transmission in invertebrates (Piomelli et al., 1987a,b; Buttner et al., 1989) suggests that the signaling mechanisms involved in modulating synaptic strength are highly conserved throughout the animal kingdom.

\section{References}

Bolshakov VY, Siegelbaum SA (1994) Postsynaptic induction and presynaptic expression of hippocampal long- term depression. Science 264:1148-1152.

Bolshakov VY, Siegelbaum SA (1995) Hippocampal long-term depression: arachidonic acid as a potential retrograde messenger. Neuropharmacology 34:1581-1587.

Bolshakov VY, Carboni L, Cobb M, Siegelbaum SA, Belardetti F (2000) Dual MAP kinase pathways mediate opposing forms of long-term plasticity at CA3-CA1 synapses. Nat Neurosci 3:1107-1113.

Borsch-Haubold AG, Kramer RM, Watson SP (1997) Phosphorylation and activation of cytosolic phospholipase $\mathrm{A}_{2}$ by $38-\mathrm{kDa}$ mitogen-activated protein kinase in collagen-stimulated human platelets. Eur J Biochem 245:751-759.

Buttner N, Siegelbaum SA, Volterra A (1989) Direct modulation of Aplysia $\mathrm{S}-\mathrm{K}^{+}$channels by a 12-lipoxygenase metabolite of arachidonic acid. Nature 342:553-555.

Cowan WM, Sudhof TC, Stevens CF (2001) Synapses. Baltimore: Johns Hopkins UP.

Chen XS, Kurre U, Jenkins NA, Copeland NG, Funk CD cDNA cloning, expression, mutagenesis of C-terminal isoleucine, genomic structure, and chromosomal localizations of murine 12-lipoxygenases (1994) J Biol Chem 269:13979-13987.

Cho H, Ueda M, Tamaoka M, Hamaguchi M, Aisaka K, Kiso YH, Inoue T, Ogino R, Tatsuoka T, Ishihara T, Noguchi T, Morita I, Murota S (1991) Novel caffeic acid derivatives: extremely potent inhibitors of 12 lipoxygenase. J Med Chem 34:1503-1505.

Drapeau C, Pellerin L, Wolfe LS, Avoli M (1990) Long-term changes of synaptic transmission induced by arachidonic acid in the CAl subfield of the rat hippocampus. Neurosci Lett 115:286-292.

Dudek SM, Bear MF (1992) Homosynaptic long-term depression in area CA1 of hippocampus and effects of $N$-methyl-D-aspartate receptor blockade. Proc Natl Acad Sci USA 89:4363-4367.

Fitzjohn SM, Kingston AE, Lodge D, Collingridge GL (1999) DHPGinduced LTD in area CA1 of juvenile rat hippocampus; characterization and sensitivity to novel mGluR antagonists. Neuropharmacology 38:1577-1583.

Fitzsimonds RM, Poo MM (1998) Retrograde signaling in the development and modification of synapses. Physiol Rev 78:143-170.

Freeman EJ, Damron DS, Terrian DM, Dorman RV (1991) 12Lipoxygenase products attenuate the glutamate release and $\mathrm{Ca}^{2+}$ accumulation evoked by depolarization of hippocampal mossy fiber nerve endings. J Neurochem 56:1079-1082.

Gasparini F, Lingenhohl K, Stoehr N, Flor PJ, Heinrich M, Vranesic I, Biollaz M, Allgeier H, Heckendorn R, Urwyler S, Varney MA, Johnson EC, Hess SD, Rao SP, Sacaan AI, Santori EM, Velicelebi G, Kuhn R (1999) 2-Methyl-6-(phenylethynyl)-pyridine (MPEP), a potent, selective and systemically active mGlu5 receptor antagonist. Neuropharmacology 38:1493-1503.

Hervieu GJ, Cluderay JE, Gray CW, Green PJ, Ranson JL, Randall AD, Meadows HJ (2001) Distribution and expression of TREK-1, a two-poredomain potassium channel, in the adult rat CNS. Neuroscience 103:899-919.

Hii CS, Huang ZH, Bilney A, Costabile M, Murray AW, Rathjen DA, Der CJ, Ferrante A (1998) Stimulation of p38 phosphorylation and activity by arachidonic acid in HeLa cells, HL60 promyelocytic leukemic cells, and human neutrophils. Evidence for cell type-specific activation of mitogenactivated protein kinases. J Biol Chem 273:19277-19282.

Kalyankrishna S, Malik KU (2003) Norepinephrine-induced stimulation of p38 mitogen-activated protein kinase is mediated by arachidonic acid metabolites generated by activation of cytosolic phospholipase $\mathrm{A}_{2}$ in vascular smooth muscle cells. J Pharmacol Exp Ther 304:761-772. 
Kishimoto K, Matsumara K, Kataoka Y, Morii H, Watanabe Y (1999) Localization of cytosolic phospholipase $\mathrm{A}_{2}$ messenger RNA mainly in neurons in the rat brain. Neuroscience 92:1061-1077.

Lujan R, Nusser Z, Roberts JD, Shigemoto R, Somogyi P (1996) Perisynaptic localization of metabotropic glutamate receptors mGluR1 and mGluR5 on dendrites and dendritic spines in the rat hippocampus. Eur J Neurosci 8:1488-1500.

Manzoni OJ, Williams JT (1999) Presynaptic regulation of glutamate release in the ventral tegmental area during morphine withdrawal. J Neurosci 19:6629-6636.

Medhurst AD, Rennie G, Chapman CG, Meadows H, Duckworth MD, Kelsell RE, Gloger II, Pangalos MN (2001) Distribution analysis of human two pore domain potassium channels in tissues of the central nervous system and periphery. Brain Res Mol Brain Res 86:101-114.

Mulkey RM, Malenka RC (1992) Mechanisms underlying induction of homosynaptic long-term depression in area CAl of the hippocampus. Neuron 9:967-975.

Normandin M, Gagné J, Bernard J, Élie R, Miceli D, Baudry M, Massicotte G (1996) Involvement of the 12-lipoxygenase pathway of arachidonic acid metabolism in homosynaptic long-term depression of the rat hippocampus. Brain Res 730:40-46.

O’Dell TJ, Hawkins RD, Kandel ER, Arancio O (1991) Tests of the roles of two diffusible substances in long-term potentiation: evidence for nitric oxide as a possible early retrograde messenger. Proc Natl Acad Sci USA 88:11285-11289.

Oliet SH, Malenka RC, Nicoll RA (1997) Two distinct forms of long-term depression coexist in CA1 hippocampal pyramidal cells. Neuron 18:969-982.

Patel AJ, Lazdunski M, Honore E (2001) Lipid and mechano-gated 2P domain $\mathrm{K}^{+}$channels. Curr Opin Cell Biol 13:422-428.

Pin JP, Duvoisin R (1995) The metabotropic glutamate receptors: structure and functions. Neuropharmacology 34:1-26.

Piomelli D, Shapiro E, Feinmark SJ, Schwartz JH (1987a) Metabolites of arachidonic acid in the nervous system of Aplysia: possible mediators of synaptic modulation. J Neurosci 7:3675-3686.

Piomelli D, Volterra A, Dale N, Siegelbaum SA, Kandel ER, Schwartz JH, Belardetti F (1987b) Lipoxygenase metabolites of arachidonic acid as second messengers for presynaptic inhibition of Aplysia sensory cells. Nature 328:38-43.

Rouach N, Nicoll RA (2003) Endocannabinoids contribute to short-term but not long-term mGluR-induced depression in the hippocampus. Eur J Neurosci 18:1017-1020.

Rush AM, Wu J, Rowan MJ, Anwyl R (2002) Group I metabotropic glutamate receptor (mGluR)-dependent long-term depression mediated via p38 mitogen-activated protein kinase is inhibited by previous highfrequency stimulation and activation of mGluRs and protein kinase $\mathrm{C}$ in the rat dentate gyrus in vitro. J Neurosci 22:6121-6128.

Sanes JR, Lichtman JW (1999) Can molecules explain long-term potentiation?. Nat Neurosci 2:597-604.

Stanton PK (1995) Phospholipase $A_{2}$ activation is not required for longterm synaptic depression. Eur J Pharmacol 273:R7-9.

Steel DJ, Tieman TL, Schwartz JH, Feinmark SJ (1997) Identification of an 8-lipoxygenase pathway in nervous tissue of Aplysia californica. J Biol Chem 272:18673-18681.

Sun D, Funk CD (1996) Disruption of 12/15-Lipoxygenase expression in peritoneal macrophages. J Biol Chem 271:24055-24062.

Talley EM, Solorzano G, Lei Q, Kim D, Bayliss DA (2001) CNS distribution of members of the two-pore-domain (KCNK) potassium channel family. J Neurosci 21:7491-7505.

Watanabe AM, Carlisle HJ, O'Dell TJ (2002) Postsynaptic induction and presynaptic expression of group I mGluR-dependent LTD in the hippocampal CA1 region. J Neurophysiol 87:1395-1403.

Watanabe T, Medina JF, Haeggstrom JZ, Rådmark O, Samuelsson B (1993) Molecular cloning of a 12-lipoxygenase cDNA from rat brain. Eur J Biochem 212:605-612.

Williams JH, Errington ML, Lynch MA, Bliss TVP (1989) Arachidonic acid induces a long-term activity-dependent enhancement of synaptic transmission in the hippocampus. Nature 341:739-742.

Yoshinara Y, Watanabe Y (1990) Translocation of phospholipase $A_{2}$ from cytosol to membranes in rat brain induced by calcium ions. Biochem Biophys Res Commun 170:484-490.

Zakharenko SS, Zablow L, Siegelbaum SA (2002) Altered presynaptic vesicle release and cycling during mGluR-dependent LTD. Neuron 35:1099-1110.

Zhu JJ, Qin Y, Zhao M, Van Aelst L, Malinow R (2002) Ras and Rap control AMPA receptor trafficking during synaptic plasticity. Cell 110:443-455.

Zink MH, Oltman CL, Lu T, Katakam PV, Kaduce TL, Lee H, Dellsperger KC, Spector AA, Myers PR, Weintraub NL (2001) 12-lipoxygenase in porcine coronary microcirculation: implications for coronary vasoregulation. Am J Physiol 280:H693-H704. 